\title{
Environmental Health vs Social Services: A Sociological Appraisal
}

\author{
Mohammad Taghi Sheykhi* \\ Professor Emeritus of Sociology, Alzahra University, Tehran, Iran
}

*Corresponding author: Mohammad Taghi Sheykhi, Professor Emeritus of Sociology, Alzahra University, Tehran, Iran

\section{ARTICLE INFO}

Received: 㓞 April 06, 2020

Published: 蔧 April 14, 2021

Citation: Mohammad Taghi Sheykhi. Environmental Health vs Social Services: A Sociological Appraisal. Biomed J Sci \& Tech Res 35(1)-2021. BJSTR. MS.ID.005648.

Keywords: Environment; Social Services; Environmental Health; Demographic Pressures; Environmental Ethics

\author{
ABSTRACT
}

Sociological evaluation of environment provides us with a clear picture of environment it is attained, how it is sustained and how it is protected. Maintenance of environment and reaching a state of environmental health depends on the behavior and education of the individuals in a society. What gives the individuals the education and behavior needed is mainly social services. Organizations such as municipalities, environmental organizations and many more play decisive roles to educate communities to protect the environment and environmental spaces. Similarly, training and providing facilities according to the conditions transfer the required education to the citizens so as to deal with the environment in a proper manner. Due to the population increase and wide urbanization at present time, environment has faced more serious changes as compared with any time in the past. Currently, urban population in more developed world is estimated to be $79 \%$, and in less developed world it is 51\% (WPDS, 2020). Environment is widely exposed to environmental degradation; both in rural and urban areas. The scenario is sociologically and widely worth investigation. As a result of citizens transportation, unfavorable transportation system, high population density, destruction of green spaces to create residential places and the like, all play role in the environmental destruction.

\section{Method of Research}

Methodology used in the present article is of qualitative type. In that, various paradigms have been used to find out about the facts regarding pandemics during the history. Qualitative research usually studies people, events or areas in their natural settings. In finding facts for the research, the researcher engaged in careful data collection and thoughtful analysis of what was relevant. In the documentary research applied for the present research, printed and written materials were widely regarded. The research was performed as a qualitative library-type in which the researcher had to refer to the relevant and related sources. In the current research, various documents were thoroughly investigated, and the needful inferences were made. The data fed by the investigator in the present article is hopefully reliable. Though literature on pandemics is very limited, yet the author tried to investigate many different resources in order to elicit the necessary information to build up the text.

\section{Introduction}

These two areas, namely social services and social health, are interrelated. Social services themselves are a field or discipline that is related to public health, or in other words, plays a role in its creation. Social health is also related to various aspects of the natural environment and the built environment; That is, it can play a role in how it is built while maintaining the natural health of the environment; That is, what has a direct impact on human health. Social services and environmental health are largely related to environmental sciences. Environmental health professionals need to use theories and ideas related to social services. Likewise, how air quality, environmental monitoring and ecological health each depend in turn on social services. Therefore, aspects and contexts of food, health and safety are considered as a roadmap for social services and environmental health [1]. In this article, two social 
contexts and environmental health are evaluated in a sociological framework. Today, due to the expansion of cities and increasing urban density, the environment is largely endangered. Therefore, just as people in society need social services, today the environment needs such services in its specialized form.

\section{Environmental Protection}

In general, environmental protection is the act of controlling the natural environment at the individual, organizational, or governmental level. Environmental protection is not only relevant to individuals in a community, but also to organizations and governments in any community. Organizations such as municipalities, environmental organizations, government attention, government funding in the relevant field, and so on, each play an important and decisive role in protecting the environment and keeping many environmental spaces natural. Similarly, the training and transfer of the necessary facilities, and according to the conditions to the citizens by the governments, causes the citizens to receive as much education as possible in how to deal with the environment. In the present era, due to the increase in population on the one hand and the shift of population to urban areas on the other hand, the environment has faced more serious dangers than ever before. Waste generation, air pollution and loss of species are considered as important factors related to environmental protection [2]. Citizens' transportation, unfavorable transportation system, high population density, destruction of green spaces to create residential places and the like, each play a role in the destruction of the environment.

Environmental protection is a barrier to the natural environment and humans; That is, it contributes to individual and social health, and promotes them. Therefore, the health of individuals in society, the well-being of citizens, how well-being of individuals in different sectors of each community depends on the health of the environment. This will improve the quality of life of citizens and society in general. Therefore, personal and social progress and development depends on investing more and more in the environment and continuous monitoring of it. Otherwise, different social strata are exposed to many harms. As far as social services are concerned, social service experts and social researchers themselves have a decisive role to play in creating such healthy social spaces. This situation has been considered and operationalized in many industrial societies during the twentieth century. Factors such as demographic pressures and technology have caused the biophysical degradation of the environment, and in some cases, it is even permanent. Population growth and the resulting pressures in the form of migration, on the one hand, and the use of different technologies to respond to population needs, in various ways, cause environmental degradation, and in some cases, its continuous decline. This kind of degradation of the environment is easily seen in large cities, and at the same time, this phenomenon is spreading to smaller urban spaces today. An appropriate recommendation has been made in this regard; The approach of information exchange, development of solution-oriented strategies and improvement of regional protection should be pursued as an approach to the protection of urban spaces [3].

This has become self-evident, and governments have subsequently begun to put pressure on activities that are detrimental to the environment. Many related organizations today, in order to protect the environment, have moved industries from within cities to outside cities. Also, changing the fuel of vehicles from liquids (diesel, gasoline, etc.) to electricity, is itself on the agenda of some governments today in order to further protect and ensure the health of the environment. The case occurred recently in Manila, the capital of the Philippines, where high-powered vehicles were experimentally electrified to prevent environmental pollution. In any case, following the pressure of the population, various industries are created inside the cities and on the outskirts of cities. The situation itself needs more monitoring and proper investment.

\section{Environmental Movements}

Since the 1960s, the activities of environmental movements have created awareness of various environmental issues. Some of the pro-environmental treaties and agreements include the Kyoto Protocol, the Vienna Convention on the Protection of the Ozone Layer, and the Rio Declaration on Environment and Development [4]. From that year on, many pro-environmental groups first established themselves in industrialized countries and gradually in other countries, thus introducing environmental protection as one of their main goals. For example, the Greens in Germany have been involved in many humanitarian activities in recent decades to protect the environment. Creating awareness in this regard helps the environment to maintain its health as much as possible. One of the latest projects in this area is the collection of waste by families and its delivery to health centers in the Philippines for free health care. In this way, the Philippine government intends to play a dual role; That is, on the one hand, it pays attention to the health and protection of the environment, and on the other hand, it pays more attention to the health of people.

While there is no consensus on the extent of the environmental impact of human activities, conservation measures are also commonly criticized. Disorders caused by the environment are abundant and increasing today. At the same time, there is less consensus or agreement on how to address them. Therefore, methods and methods must be adopted through which the challenges and increasing means of the environment can be controlled and controlled. The debate over environmental protection places more emphasis on the role of governments, laws, and law enforcement [5]. Today, many academic institutions offer courses such as environmental studies, environmental management, and environmental engineering to teach history 
and methods of environmental protection. Since the complexities of the environment are constantly increasing, and their number and number are increasing every year, in order to deal with such complexities, adopting scientific and academic methods of the mentioned type is very necessary and instructive. However, many less developed countries do not have such educational and research institutions and centers and are less able to invest in this regard. At the same time, social service professionals, to a large extent, cannot provide an image to environmental planners by identifying the issues that are going on around them and within communities; In this way, many emerging issues and challenges within communities can be controlled and minimized.

Environmental protection is required due to various human activities. Urban communities have become more vulnerable than ever in the past following the development of industrialeconomic activities, the physical expansion of cities, the increase of economic activities and the like; That is, a situation that itself needs to take measures related to environmental protection. The situation is such that part of its social services is focused on environmental protection and environmental health. At the same time, many countries' constitutions affirm the fundamental right to environmental protection, and many international treaties recognize the right to live in a healthy environment [6]. Waste production, air pollution and lack of biodiversity, which is the result of the loss of many plant specimens, etc., are some of the issues related to environmental protection; It is a stream that endangers the health of the environment itself, and in return requires a variety of social services. Following the complication of socio-economic life in the present age and the creation of various types of air pollution, the destruction of green and plant spaces and other conditions of this kind, the provision of better social services and environmental monitoring, to a large extent to individual health and socially helps in general. On the other hand, environmental planners today need to strike a reasonable balance between urban and rural residents, especially in less developed countries. In this way, the burden of pollution in urban areas can be reduced, and as a result, environmental protection is achieved implicitly.

\section{Factors Affecting Environmental Protection}

Environmental protection itself is influenced by three intertwined factors

\section{a) Environmental legislation \\ b) Environmental ethics \\ c) Environmental education}

Each of these three contributes in turn to environmental health, that is, what ultimately leads to social health. Therefore, environmental health and social health also interact with each other. Similarly, in order to create a healthy environment, social grounding in its various forms must be done.
Each of these factors influences environmental decisions at the national level and environmental values and behaviors at the individual level. Environmental health affects social interactions, norms, as well as lifestyles at different levels. In other words, these factors (environment) affect individual and social health. Therefore, the introduction of new patterns and values and what is common today as environmental patterns, itself provides more guarantees for social health. Over the last half century, many societies (especially developed societies) have adopted new policies, based on which they have taken action to improve their environment. In other words, a new kind of environmental culture has been created with its own patterns in these societies, the effects of which will eventually return to the relevant citizens. In order for environmental protection projects to take place and be implemented, different communities must, depending on the circumstances, develop each of these areas; It is a process that collectively leads to environmental decisions. Issues such as environmental legislation, environmental ethics, environmental education, and practices such as these provide the emergence of a new kind of culture that ultimately contributes to environmental health; It means a set of conditions in which individual and social health is also ensured. Due to the industrialization of societies, the complexity of societies, the enlargement of cities, the increase of cultural diversity, race and the like, especially in urban areas, achieving environmental health should be a priority in socio-environmental plans and programs.

\section{Environmental Legislation}

Environmental law or legislation, which is itself a collective term, describes international treaties, laws, bylaws, etc., or as required by the national legislature. Many environmental laws have a global and international dimension that must be enforced, and it is necessary to pay attention to written laws, contracts and the like. At the same time, countries in many cases adopt and recommend national and domestic laws and regulations to protect their environment. It is also worth noting that in the absence of adherence to many international environmental laws and treaties, many of the consequences and consequences of environmental health reach other societies and countries; In a way, they are also negatively affected. The laws of the environment are applied to ensure proper interaction between humans and the environment naturally. This movement is aimed at reducing the effects of human activities and is itself a kind of infrastructure of social services. Enforcing environmental laws somehow develops and provides social services. Therefore, services, human and natural resources must always be under proper supervision and regulation. At the same time, the various activities of human beings in various sectors of industry, communications, transportation, etc., must be carried out under the supervision and regulation in accordance with the temporal and spatial conditions. In this way, the destructive effects of human activities and the environment can be reduced. Environmental legislation covers two major areas or issues 
a) Pollution control and remediation

b) Conservation of resources and personal exhaustion

Most of the environmental laws try to keep the environment as healthy as possible according to the two mentioned above; In such a way that all members of society can benefit from its results. While the range of environmental laws is very wide, the most important and oldest law in this field is the Clean and Safe Water Law.

This part of the law on the environment is generally a priority in all parts of the world. Different communities, according to their circumstances, try to provide their citizens with access to safe water. It is noteworthy that different countries can provide this part of the environment for their citizens according to their capabilities. A historical look at the laws of the environment in ancient societies indicates that access to safe water was enshrined in ancient Roman law. These laws were applied in Europe in the Middle Ages (between the ages of 5-15 AD). Such social services have been practiced in Europe since the Middle Ages. It is noteworthy that during this period, the construction and maintenance of reservoirs, swamps and the like has always been emphasized in Iran. At the same time, fragility and vulnerability to the environment have been largely recognized since the 1960s, and subsequent legislation has been enacted and enforced. At the same time, population growth and urbanization, population density and such factors have created many complexities and problems in the field of environment in recent years. Increasing public awareness due to the impact of industrial activities and the like, has led to the enactment of environmental laws. Likewise, the prospect of this situation itself has led to serious environmental laws, especially among the developed nations; That is, what is itself a set of social services.

\section{Environmental Laws by Country}

Environmental issues vary from region to region; For example, African countries are more prone to drought, flood, air pollution, deforestation, species loss, drinking water scarcity, soil degradation, poor cultivation, and widespread poverty. Given the above, developing countries need a set of different plans and programs in order to keep their environment healthy. Brazil also established the Ministry of Environment in 1992 to better develop its environmental protection strategy, use its natural resources sustainably, and implement its general environmental policies. The European Union, with 28 member states, has enacted national laws to achieve greater environmental health as follows; Namely: air pollution prevention, water protection and management, waste and waste management, soil protection, nature protection, plant and animal samples, biodiversity, noise pollution, cooperation with countries in the field of environment and the like. These are just some of the goal setting shareware that you can use. It should be noted that other global communities should also consider these issues and invest in those areas to protect their environment.

\section{Environmental Ethics}

Environmental ethics is considered as a part of environmental philosophy that expands its field of moral activities from the field of purely human world to the field of non-human world [7]. This means that environmental ethics in various ways declares its support for green space, other non-human beings, and the relationship they have with each other. Environmental ethics is a set of influential fields including environmental law, sociology and environment, jurisprudential ecology, ecological economics, geography related to the environment and so on. Therefore, this scientific field creates a significant relationship between the mentioned scientific indicators in order to follow the social movement in a desirable way. Environmental ethics emphasizes the following

a) Forest resources should be preserved because of its importance and human consumption.

b) To what extent should the production of gasoline vehicles be continued?

c) What environmental requirements should be adhered to for future generations?

d) Is it true that for the convenience of humans, it mainly causes the extinction of plant specimens?

e) How to maintain the environmental space to achieve longer life. At the same time, environmental degradation is detrimental to human health now and in the future [8-14].

The academic field of environmental ethics matured in response to the work of scientists such as Rachel Carson in 1970, as well as the naming of Earth Day in 1970. Other scholars such as Lynn Waits (1976) and Garrett Hardin (1968) has been instrumental in introducing environmental ethics. Alan Marshall and Michelle Smith have also made significant contributions to the introduction of environmental ethics. While modern societies have expanded significantly physically and socially over the last 40 years, and human societies have become more complex, all of the above require that ethics and the environment be introduced and applied as much as possible.

\section{Environmental Education}

This article refers to organized efforts to see how the natural environment develops and functions, and how humans should respond to the ecosystem in order to live a more sustainable life. Environmental education begins in the school environment and can be extended to education to the general public, and is transmitted through written materials, websites, news media, and the like. Environmental education is a learning process that increases people's knowledge and awareness about the environment and its related indicators. Skills and specializations increase through environmental education. In this way, public attitudes, motivations, 
and commitments are nurtured, so that they can subsequently make sensible decisions, and take responsible action. Environmental education is not only achieved through classes, but also through field trips to national parks, travel clubs and the like. In general, environmental education in its present age is recognized as one of the basic needs of society, especially urban communities.

\section{Conclusion}

There must be a wise balance between the built environment and natural environment. Sad to say, the world is witnessing an increasing built environment at the cost of environmental degradation. Environmental health is sustained through people's knowledge and awareness. One of the human's needs at present time is to sustain a healthy environment. If not so, increasing threats would be awaiting human life. It is now somehow emerging in some countries in Asia, where the environment is sacrificed for further development and access to more GNP. Countries today need to focus on environmental ethics in order to support the life of green space, and other non-human beings and the relationships they have with each other.

\section{References}

1. Bookchin M (1990) The Philosophy of Social Ecology. In: Bookchin M (Eds.), Montreal: Black Rose Books.

2. (2001) California Institute of Public Affairs (CIPA). An Ecosystem Appraisal to Natural Resource Conservation in California. pp. 106.

\section{ISSN: 2574-1241}

DOI: 10.26717/BJSTR.2021.35.005648

Mohammad Taghi Sheykhi. Biomed J Sci \& Tech Res

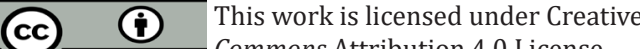

Commons Attribution 4.0 License

Submission Link: https://biomedres.us/submit-manuscript.php
3. Carson R (1963) Silent Spring. In: Carson R (Eds.), London: Hamish Hamilton.

4. Harding R (2006) Ecologically Sustainable Development: Origins, Implementation and Challenges. Desalination 187(1-3): 229-239.

5. Hardin, Garrett (1968) The Tragedy of the Common. Science 162(3859): 1243-1248.

6. Makenzie JS (2018) One Health: The Human-Animal-Environment Interfaces in Emerging Infectious Diseases, Dordrecht. In Makenzie JS (Eds.), Springer, Germany.

7. Mautner MN (2009) Life-Centered Ethics and the Human Future in Space, Bioethics 23(8): 433-440.

8. Mitchell RB (2003) International Environmental Agreements: A Survey of their Features, Formation, and Effects. Annual Review of Environment and Resources 28(1543-5938): 429-461.

9. Norton B (1995) Ethics on the Ark. In: Norton B (Eds.), Washington: Smithsonian Institution Press, USA.

10. Passmore J (1974) Man's Responsibility for Nature. In: Passmore J (Eds.), ( $2^{\text {nd }}$ Edn.), Duckworth, London.

11. Solomon U (2010) A Detailed Look at the three Disciplines; Environment Ethics, Law and Education to Determine which Play the Most Critical Role in Environmental Enrichment and Protection. Environment Development and Sustainability 12(6): 1069-1080.

12. Verschuuren J (2019) Environmental Law, Articles.

13. White L (1967) The Historic Roots of Our Ecologic Crisis. Science 155(3767): 1203-1207.

14. (2020) World Population Data Sheet. Population Reference Bureau, Washington DC.

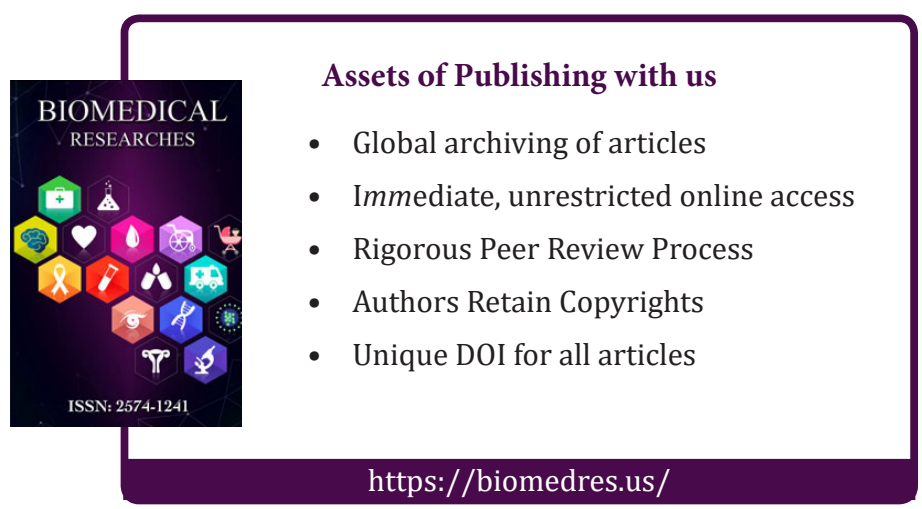

